\title{
Anthropological Researches by Academician Aleksandre Javakhishvili
}

\author{
Bitadze Liana \\ Head of the Laboratory of Anthropological researches, Institute of History and Ethnology, Tbilisi, Georgia
}

Email address:

lia.bitadze@mail.ru

To cite this article:

Bitadze Liana. Anthropological Researches by Academician Aleksandre Javakhishvili. Earth Sciences. Special Issue: Modern Problems of Geography and Anthropology. Vol. 4, No. 5-1, 2015, pp. 8-12. doi: 10.11648/j.earth.s.2015040501.12

\begin{abstract}
Aleksandre Javakhishvili, a Georgian scientist of the beginning of the XX has established quite high standards in research methodology of Anthropology. He was the first who studied Kartvelian (Georgian) ethnographic (Kartlian, Kakhetian, Gurian, Mingrelian, Imeretian, Rachian, Mtiuletian) groups by use of different fields of sciences (History, Geography, Linguistics, Ethnology). He formulated a programme for researches in the Caucasian Anthropology; raised an issue of the necessity to found a scientific-public organization that would systematically study the anthropology of the Caucasus and its neighboring regions; he was the first who marked the autochthony of the Caucasian race; distinguished the western, eastern and metamorphic anthropologic types among Georgians; studied the dolichocephalism among Georgians; carried out researches about the local peculiarities of the settlements in the Georgian Caucasus and geographical distribution of the population.
\end{abstract}

Keywords: Ethnic Anthropology, the Caucasian Race, the Kartvelian Group, a Vertical Settlement of Population

\section{Introduction}

Aleksandre Javakhishvili began his scientific work by physical type of study of the ethnographic groups of Georgians. The sphere of his interest was mainly Ethnic Anthropology and the Caucasus region. In spite of that the list of his anthropological works is not quite long they are of great importance even today. Aleksandre Javakhishvili was the first who took up a complex study of Georgians. This work is exemplary even nowadays due to the representativeness of the researched groups regarding the connection of morphological changes and age, etc.

Aleksandre Javakhishvili's works were published at the beginning of the previous century and they immediately attracted attention due to their scientific value. In 1906 and 1912 the scientist was awarded the highest scientist prize for that time - Professor A. Rastsvetov Premium. It is noteworthy that the types distinguished by him among Georgians and their similarity to one another coincide with modern standards; the difference is just in the type names. Therefore, we suppose that it is necessary to introduce Aleksandre Javakhishvili's personality and his merits for development of the science in Georgia to the young scientists interested in Physical Anthropology. It is also important to make aware our foreign colleagues of the History of
Anthropological Studies in our country.

\section{Materials}

The material used in this work is the publications on anthropological researches by Aleksandre Javakhishvili. It is noteworthy that he was the first scientist who obtained numerous qualitative and measurement data about Kartlians [1], Kakhetians [2], Gurians [3], Mingrelians [4], Imeretians, Gurians and Rachians [5]. He studied 107 descriptive and measurement features of hundred males in each group; considered the distribution of morphological features according to different age groups and average properties of ethnographic groups; studied interrelation of some measurement features and their connection with the age.

\section{Results and Discussions}

\subsection{Study of Different Ethnographic Groups of Georgia}

The outstanding Georgian scientist Aleksandre Javakhishvili was interested in Ethnic Anthropology. Among his anthropological works the fundamental researches on the Georgian Ethnographic groups are the most significant (Fig. $1,2)$. As far as they organically combine data of different spheres of science (History, Geography, Linguistics, 
Ethnology) they are actual even nowadays.

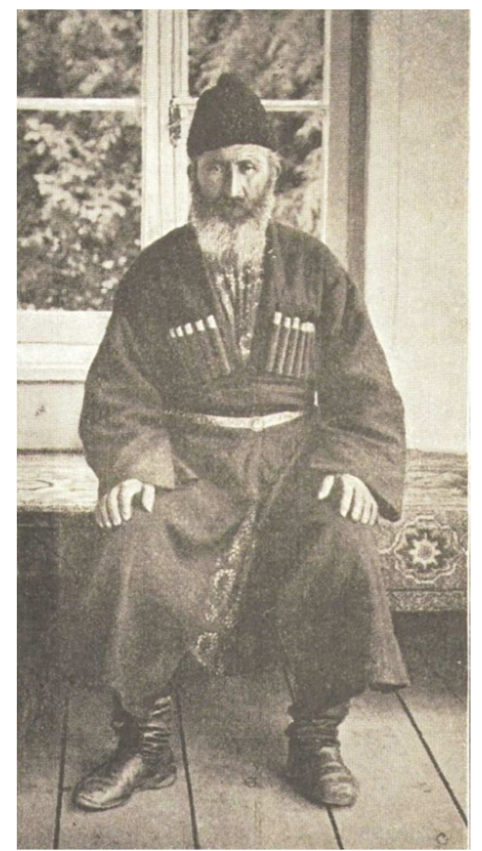

Figure 1. Kartvelian form Dzevera (Kartli).

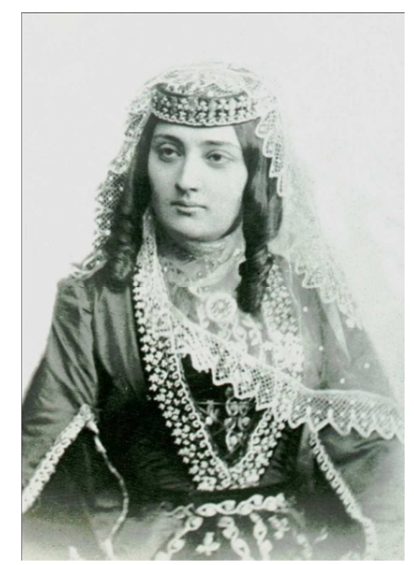

Figure 2. Kartvelian.

These works prove that the ethnographic groups of Kartvelians (Georgians) do not have many differential features from one another and even if there are any they are quite inessential. In the scientist's opinion Georgians represent a different and independent anthropological group, which he named a Kartvelian group [1,2]. Despite their similarity the features of Georgians significantly vary and this group may be divided in two main types. The first type is met in Mingrelia, Guria and Imereti (the western parts of Georgia) and the other - in Kartli and Kakheti (the eastern parts of Georgia). The difference in features among the Kartvelian groups of Mingrelia and Kakheti is the most striking (Fig. 3, 4).

Rachians and Mtiuletians are mixed types, which in some cases have medium features. However, sometimes these features are represented either as the western or the eastern type [6]. In the work dedicated to Mingrelians [4] Aleksandre Javakhishvili marks the variation of anthropological features linked with the age. Mainly, the more the age the darker the skin and the less the height of the body, head, forehead, width of the face, the length of the nose; the features of the population in the age of 26-35 mostly correspond to the average measures of the group; existence of fair-haired and blue-eyed and dark-haired and dark-eyed types among the population in the West of Georgia [4] is marked (Fig. 5, 6, 7 ).

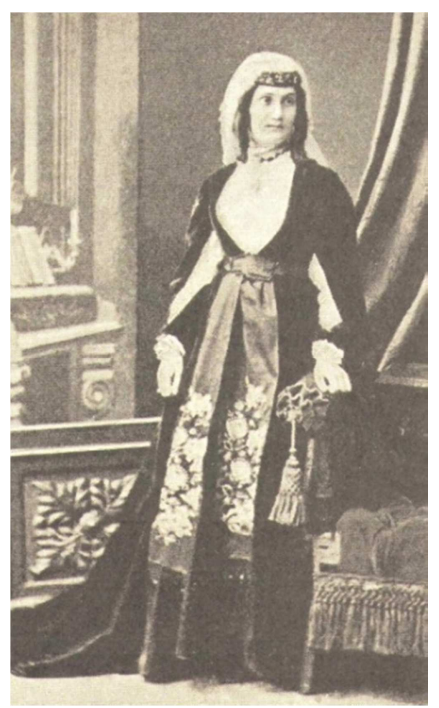

Figure 3. Kartvelian form Kakheti.

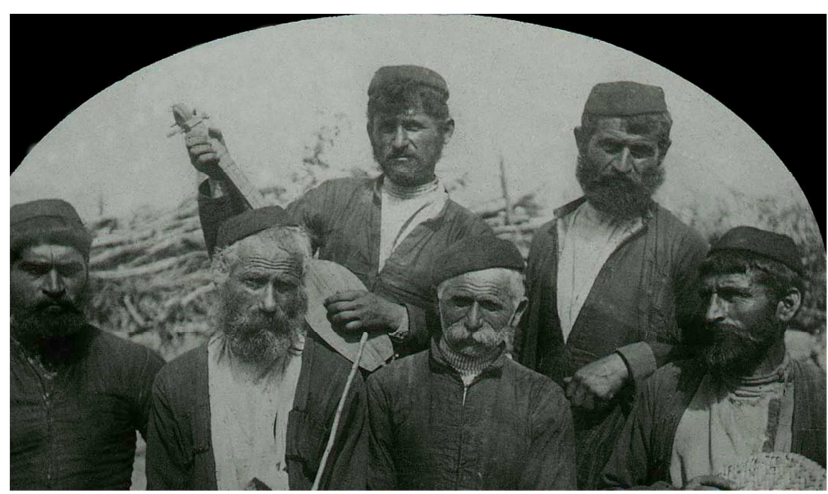

Figure 4. Kartvelians form Vachnadziani and Kalauri (Kakheti).

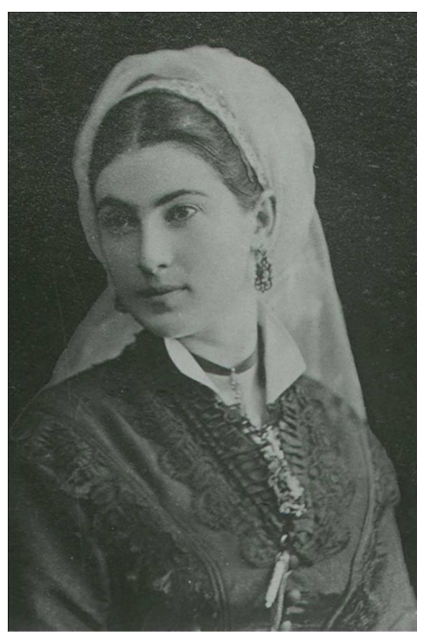

Figure 5. Kartvelian form Guria. 


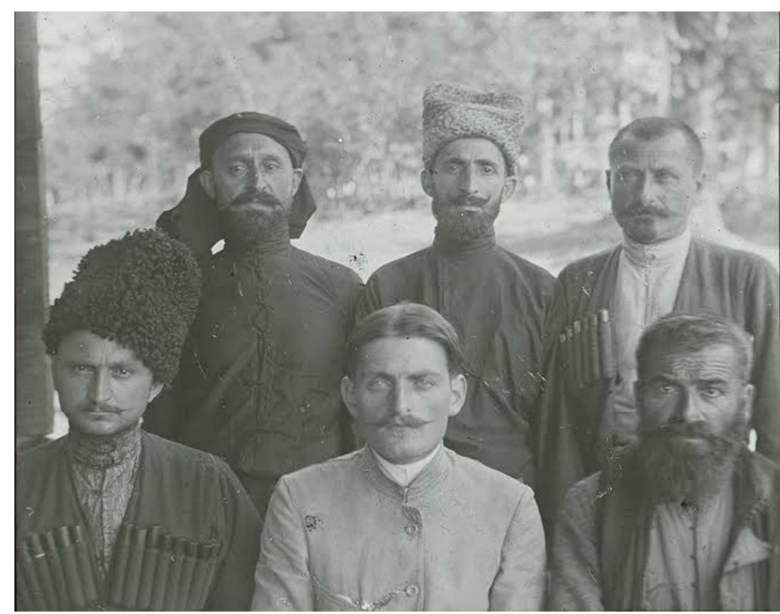

Figure 6. Kartvelian form Chokhatauri (Guria).

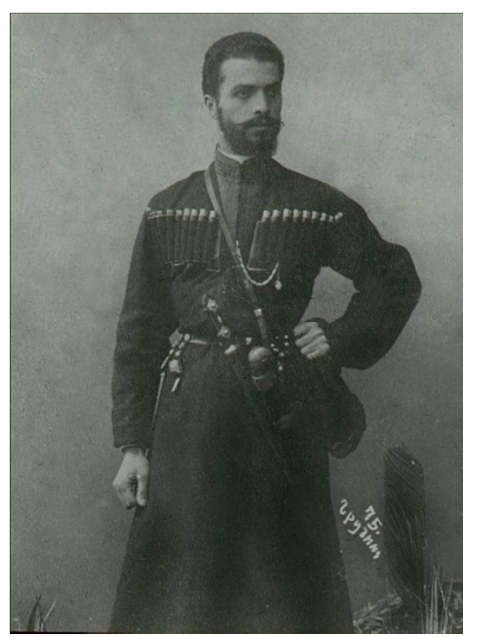

Figure 7. Kartvelian form Imereti.

Analyzing his work "The Anthropological Composition of the Modern Caucasian Population" Aleksandre Javakhishvili marks: "In the Caucasus Georgians, Azerbaidjanis, Russian-Kazaks and Nogais have opposite, different features" [6]. Their features were studied according to hair and eye color, longitudinal and latitudinal circumference of head, head indicator, height of face, width of face and face indicator. These four Caucasian nations bear the features of different ancestries. It is obvious that Georgians are the indigenous nation of the Caucasus and the roots the Georgians have developed from must be considered as an autochthonous ancestry of the Caucasus. This is the ancestry, from which other Caucasian autochthonous nations have developed and are related with Georgians by racial links. Therefore he called it the Caucasian race.

The scientist compares the Caucasian and other racial groups according to the height of the mid third of face, nose indicator, inter-eye space width, height, body length, breast circumference, shoulder width, arm length, wrist length, leg length and foot length. It is noteworthy that Georgians, Circassians, Lezgians (Dagestani) and Jews are represented by several groups while Karachais, Armenians, Assyrians, Ossetians, Chechens, Ingushs, Kumuchs and Uds - by a single group. As a result of comparison the scientist gives an anthropological classification of the modern Caucasian population. He divides the Caucasian race into Kartvelian (Georgian), Circassian, Lezgian and Armenian anthropological groups and the groups into Anthropological types. Some ethnic groups (Ossetian, Chechen, Ingush) not fully expressing the anthropological peculiarities characteristic of the Caucasian race are bearers of the mixed type of features. He calls them a metamorphic type [6] (Fig. 8, 9).

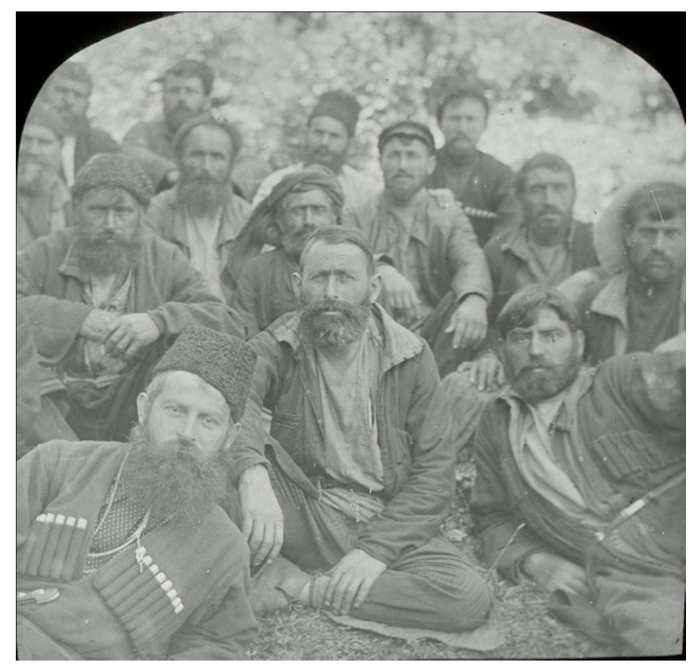

Figure 8. Kartvelian form Shkmeri (Racha).

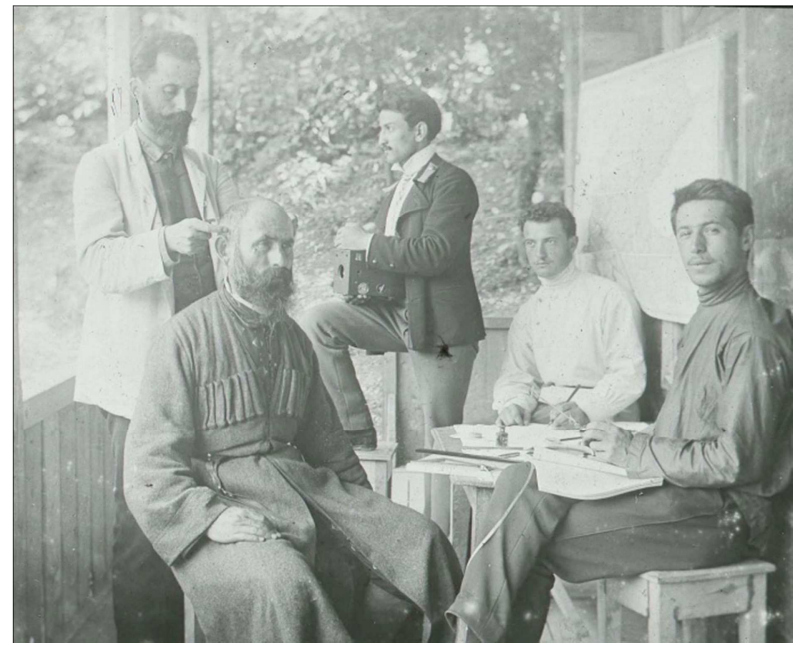

Figure 9. Kartvelian form Tsesi (Racha).

The scientist has made a special research [7] on the issue of the Caucasian race and has marked anthropological differences among the ethnic groups combined in it. The variety of some characteristic features makes each of them special. In each considered nation, in its ethnic limits, instability of its features (saying in modern terminology variation of features, as all groups are polymorphic) is observed. Furthermore, he reveals a very significant fact that the anthropological features gradually vary in the Caucasian space from west to east and from north to south. These gradual changes prove that the variations of the Caucasian race have locally generated and developed. It refers to autochthony of the race. The Caucasian unity regarding this 
point of view is proved by modern researches as well [8], though this issue has been considered by Aleksandre Javakhishvili for the first time.

The scientist works "Armenians in the View Point of Anthropology" [9], "The Jews of the Caucasus [10], "The Dolichocephalism among Georgians" [11] and reviews emphasize his erudition and relation to the current processes in Anthropology.

\subsection{Programme for Caucasus Study}

His report "The Tasks of the Anthropological Researches on the Caucasus" [12] are of great importance as the scientist has formulated a programme for Caucasus study in it. $\mathrm{He}$ writes: "The study of the Caucasian population must comprise all the ethnic groups together with their variations; inter-morphological relation among certain groups and racial composition of the population must be determined; the study of the ancient population must be conducted according to historically sequential epochs, variation of anthropological types and sexual dimorphism of anthropological features; influence of geographical, social and historical conditions on the human body and mentality must be revealed". The scientist also considers the necessity to found a scientific-public organization that would systematically study the anthropology of the Caucasus and its neighboring regions.

\subsection{Revies of Aleksandre Javakhishvili's}

Aleksandre Javakhishvili's review of A. Dirr's "The Anthropological and Ethnographic Composition of the Caucasian People" [13] is to be distinguished. A. Dirr writes that the Caucasus is not the birthplace of the Caucasian race but a shelter for those settled here". To this viewpoint Aleksandre Javakhishvili responds that the author of the article is quite ignorant of the history of the Caucasus. However, it does not prevent him to persuade his reader that the Caucasia is no birthplace of the Caucasians. Does not the author know anything about Colchis, Lazistan, Caucasian Iberia, Caucasian Albania, Armenia and Pontus? A. Dirr shares I. Pantyukhov's anthropological classification, which, in its turn, is based on such "limited" data as a head indicator, body height and eye pigmentation. The racial composition of the Caucasian nations (as well as of any nations, L.B.) cannot be determined on the bases of such poor data (modern Anthropology has accepted a complex of features that differentiates big races, etc., L.B.) "Moreover, during the last 10 years many substantial works have been published" Aleksandre Javakhishvili writes and at the same time adds that ignorance in the history of the Caucasus, not knowing the new data, not having any critical attitude to anthropological materials, biased and arbitrary use of primary data makes it impossible to perceive the real image of the anthropological composition of the Caucasian population.

A. Javakhishvili has also written reviews of different types of works on methodological and anthropological issues: "For technology of taking hand prints and foot prints" by
Professor Otto Flagginsuphen, "A simple way to take a foot print" by Doctor Muscat, "On development of the bones of Incas" by Otto Eichel, "Hair distribution in eyebrows" by Hans Virkhov, etc. [14].

\subsection{Vertical Distribution of the Population}

A. Javakhishvili's work "Vertical Distribution and Division of the settlements and population in the Georgian Caucasus" [15] is quite noteworthy. One of the factors of the medium is hypsometric location. The main factors for a mountainous medium are low temperature, humidity, landscape peculiarities, geo-chemical nature, in regard to which the population develops adaptation complexes. In his conclusions the scientists says that the distribution of settlements and population depends on the distribution of gorges; settlements are developed in a successive vertical way; the height of population increases from west to east and from south to north; in some height levels the number of household members and their height increase, though in some regions their number stays the same; the number of settled areas, households and the number and measures of household members, also average number of children depend on the regions of the Caucasus and their height levels. It is noteworthy that Aleksandre Javakhishvili verified the number of those settled areas that were not marked on the map or in the 1930 list of the Executive Committee. These data are significant even today as they are indicators to the demographical change in the Georgian Caucasia since the gorges have been abandoned and the inhabitants of the mountainous regions have moved to lowlands. The work based on geographical and demographical data is also of great significance for Physical Anthropology as the role of geographical medium in the development of morphological features is well known. The anthropological type of the Caucasus has been developed exactly in the high mountainous medium [16]. According to the modern classification Rachians and Mtiuletians of the highlands belong to the Caucasian type together with other mountain inhabitants of Georgia and Caucasia. Aleksandre Javakhishvili considers Mtiuletians, Rachians, Chechens, Ingushs and Osetians as a metamorphic type and says that the types met in West and in the East of Georgia correspond to the Colchian and Iberian types [17] classified by $\mathrm{M}$. Abdushelishvili.

\section{Conclusion}

Aleksandre Javakhishvili is the first Georgian anthropologist who made the foundation for substantial studies of Georgians. He distinguished the western, eastern and metamorphic types among Georgians; for the first time marked the links between anthropological features and age, dolichocephalism among Georgians, aboriginality of the Caucasians; studied the Caucasian race; wrote a programme for the anthropological study of the Caucasia, where he considered it necessary to study the ancient population according to historically gradual epochs, study of all modern 
ethnics according to territorial groups, foundation of scientific-public organization. He researched the local peculiarities in the geographical distribution and division of settlements and population in the Georgian Caucasia.

It is noteworthy that division of Georgians in three types by Aleksandre Javakhishvili at the beginning of the XX century was quite correct. Despite significant methodic changes his scientific instinct and point of view have turned out to be true. On the basis of the study of 63 territorial groups of Georgians and 118 Caucasian groups by $\mathrm{M}$. Abdushelishvili in the 50-ies of the XX century the Caucasian nations were originally classified [17]. Aleksandre Javakhishvili's method for the study of the Caucasian population has been successfully used, though the territorial groups of some ethnics have not yet been studied completely. This branch of science is developing and the methods for studies of modern and ancient populations have been improved as well. Anthropology in its research limits has involved many branches of modern sciences and therefore has become an all-encompassing science for human studies.

\section{Acknowledgements}

The author thanks the Museum of Geography of Ivane Javakhishvili Tbilisi State University for photos (2, 4-9).

\section{References}

[1] Javakhov A. N. Anthropology of Georgia. Kartlians. Russian Anthropological Journal, № 3-4, 1905. pp. 1-46. (in Russian).

[2] Javakhov A. N. Anthropology of Georgia. Georgians of Kakhetia. Russian Anthropological Journal, № 3-4. 1907. (in Russian).

[3] Javakhov A. N., On Anthropology of Georgia. Georgians of Guria. Russian Anthropological Journal, № 2-3. 1912 a. (in Russian).

[4] Javakhov A. N., On Anthropology of Georgia. Georgians of Mingrelia. Russian Anthropological Journal, № 1-2. 1913 a.

[5] Javakhov A. N., Anthropology of Georgia. II. Georgians of
Imeretia, Guria and Racha. Proceedings of the Imperial Society of Naturalists, Anthropology and Ethnography, published by Moscow University, vol. CXXVIII, M., 1914. p. 246. (in Russian).

[6] Javakhishvili A.,. The Anthropological Composition of the Modern Population of Caucasia. Medicinal proceedings of Georgia, Tbilisi, №3, 1923 a. p. 18-42.

[7] Javakhishvili A., The Caucasian Race. Proceedings of Tbilisi State University, vol. III, 1923 b. pp. 63-81.

[8] L. Bitadze, Sh. Laliashvili. 2014. Caucasian Unity from the Anthropological View. $44^{\text {th }}$ Congress of the International Society for the History of Medicine. The Great Silk Road \& Medicine, 10-14 September 2014, p. 49, Tbilisi, Georgia.

[9] Javakhishvili A., Armenians in the Anthropological Point of View. Proceedings of Tbilisi State University, vol. III, 1924. pp. 63-81.

[10] Javakhov A. N., Caucasian Jews. Russian Anthropological Journal, № 4. 1912 b. (in Russian).

[11] Javakhov A. N., Caucasian Jews. Russian Anthropological Journal, №3-4. 1913 b. (in Russian).

[12] Javakhov A. N., Tasks of Anthropology of Caucasia. In Alexandre Javakhishvili's Works, volume I. papers on Anthropology, 1913 c. pp. 130-131.

[13] Javakhov A. N., Review of A. M. Dirr's article "Anthropological and Ethnographical Composition of the Caucasian Nations", In Alexander Javakhishvili's Works, volume I. papers on Anthropology, pp. 287-291.

[14] Javakhishvili A., Proceedings. Anthropological Works, vol. I, Tbilisi, 1990, pp. 292-294; 296-297; 301-302.

[15] Javakhishvili A., 1963, Vertical Distribution and Division of Settlements and Population in Georgian Caucasia. Proceedings. Anthropological Works, vol. I, Tbilisi, TSU, 1990, pp. 252-286.

[16] Natishvili A. N., Abdushelishvili M. G., On the Anthropological Composition of the Modern Population of Georgia. Reports at Scientific Session of Department of Biology and Medical Sciences, Tbilisi, 1953. pp. 37-41.

[17] Abdushelishvili M. G., Anthropology of the Ancient and Modern Population of Georgia. Tbilisi, Metsniereba, 1964. 208 pp. 